\title{
Pro-environmental Printing Behaviour as an Indicator to Reduce Paper Cost at Work
}

\author{
Javed Iqbal Suleri ${ }^{1^{*}}$ \\ 1 Stenden University of Applied Sciences, Rengerslaan 8, 8917 DD Leeuwarden, NETHERLANDS \\ *Corresponding Author: jisuleri@yahoo.com
}

Citation: Suleri, J. I. (2018). Pro-environmental Printing Behaviour as an Indicator to Reduce Paper Cost at Work. European Journal of Sustainable Development Research, 2(3), 38. https://doi.org/10.20897/ejosdr/2670

Published: July 17, 2018

\begin{abstract}
Today we are facing environmental hitches such as deforestation and global warming, due to which atmospheric $\mathrm{CO}_{2}$ level has increased by $25 \%$ since 1850 . It is human activities that have created these problems; hence, the resolutions to these encounters lie in behavioral change. Thus, it is only by empowering people that the environment can be protected. This study aims to explore reduction of printing at elementary schools by enhancing pro-environmental printing behavior. Literature review is presented in the following themes - demographic, impact of printing on the environment and pro-environmental printing behavior. An observation method is applied in this study and data is obtained from 108 teachers from seven elementary schools at three different regions in Northwest Friesland, The Netherlands by using digital print data and printers' observation. The main findings illustrate that pro-environmental behaviour has a positive effect on the printing behavior. This research reveals that the experimental group printed $45 \%$ to $51 \%$ less during intervention. Therefore by extending pro environmental behaviour, financial and environmental costs can be minimized. This reading recommends directors of the schools to enhance pro-environmental printing behaviour among teachers to reduce both financial and environmental costs measured as use of paper.
\end{abstract}

Keywords: onscreen reading, green printing, pro-environmental behavior, consumer behaviour and environmental sustainability

\section{INTRODUCTION}

Today we are facing environmental hitches - deforestation and global warming, due to which atmospheric $\mathrm{CO}_{2}$ level has increased by $25 \%$ since 1850 . As a matter of fact, these problems are created by human activities; thus, the resolutions to these encounters lie in changing behavior (Gifford, 2011). Pro-environmental behaviour is recognized as the heterogeneous for a number of reasons - participation levels, diverse goals and direct vs indirect type of impacts (Larson et al., 2015; Poortinga et al., 2004; Stern, 2000). Such behavior on the one hand, harms the environment as little as possible and on the other hand, it even benefits the environment (Steg and Vlek 2009). For instance, reducing paper use and improving paper purchasing and handling is a 'win-win'scenario - it cuts costs and reduces environmental impacts (Citigroup, 2004; Dee, 2010; Thompson, 2009). Furthermore, promoting green printing is based on pro-environmental approach and behaviour.

There are limited studies regarding pro-environmental printing behavior and therefore, the intention of this study is to explore teachers' pro-environmental printing behaviour to reduce paper cost at the elementary schools by enhancing teachers' pro environmental printing behaviour. Previous studies prove that onscreen reading can reduce $45 \%$ paper use (Kutami, 2009). As a result, it can be said - less use of paper means less cutting of trees which will lead to a sustainable approach of life (Dee, 2010). Sustainability means "to live our life in a way that all actions we take do not reduce the possibilities for others to live their lives, without regard of where they live or 
when they live" (Brundtland, 1987, para. 4). In other words, we should live, protect and respect our life in such a way if it comes back to you later on, you will welcome it, cherish it and admire it (Suleri, 2013).

Many studies have shown that values contribute to explain various environmental behaviors and attitudes. Values are significantly correlated to various self-reported behaviors - recycling behavior and consumer behavior to protect the environment (Karp, 1996). It is people's willingness to take action to protect the environment (Dunlap et al., 1983; Stern and Dietz, 1994). Hence, we can protect environment by empowering people (Tan, 2016).

This study took place in the Northwest Friesland, The Netherlands, consisting of seven different elementary schools; some of which are small, whereas, others are substantially large. Schools are well-equipped with modern equipment, which is updated on a fairly regular basis. Nevertheless, this does not, in itself, guarantee ICT integration in education. Another feature, pro environmental behaviour of teachers also plays a very vital role. There is no point in showing teachers assimilation in their work if the reason for doing so is not understood by them (Veen, 1993a; Veen, 1993b).

This reading has a possible contribution to existing research. Furthermore, it is expecting to help teachers to realize that by extending pro environmental behaviour, financial and environmental costs can be minimized.

Considering the aforementioned facts, the central questions of this study are as follows:

$>$ What is the economic and environmental impact of reduction in printing at elementary schools?

$>$ What is the effect of pro-environmental behaviour in reducing printing?

To test this notion, the following hypothesis is used:

H1: Teachers' pro-environmental printing behaviour can reduce environmental and financial costs at elementary schools measured as use of paper.

\section{REVIEW OF LITTERATURE}

The focus of this literature review is on the main themes of this study - Impact of printing on the environment and pro- environmental behavior.

\section{Impact of Printing on the Environment}

The idea of green printing is based on pro-environmental approach. $90 \%$ of paper used for printing is "virgin," meaning it does not contain any proportion of recycled elements; it is made of wood pulp from trees (Citigroup, 2004). The manufacturing process for virgin paper is water-intensive (Dee, 2010). Producing one sheet of paper can require over 13 ounces of water which is more than enough to fill a beverage can. To be exact, reducing paper use and improving paper purchasing and handling is then a "win-win" scenario - it cuts costs and reduces environmental impacts (Citigroup, 2004; Dee, 2010; Thompson, 2009). Therefore, paper and other raw materials should come from environmentally sound sources (Tan, 2016).

Trees eliminate carbon dioxide from the air and convert it into carbon via photosynthesis, which is then stored in the wood of trees in a process known as carbon sequestration which can reduce global warming. Trees are a major natural carbon storage, their removal reduces the ability to produce oxygen (Gregory, 1971). Thus, less use of paper means less cutting of trees which will lead to a sustainable approach of life (Dee, 2010). Sustainability means "to live our life in a way that all actions we take do not reduce the possibilities for others to live their lives, without regard of where they live or when they live" (Brundtland, 1987, para. 4). Furthermore, the whole concept of the earth is like a big balloon and the economy and ecology being the small balloons. Consequently, whilst printing and using paper, environmental and economic aspects should be considered and not only the convenience. So that the ecologic balloon will not be smothered or burst (Cavagnaro and Curiel, 2012).

To be precise, enhancing pro environmental printing behaviour in the school could lead to reduce costs both financially and environmentally (Citigroup, 2004; Dee, 2010). Although green printing at school will not make schools hundred percent sustainable, it would contribute to have a better environment in the school.

\section{Pro-environmental Behavior}

Pro-environmental behaviour is increasingly being recognized as the heterogeneous nature of for a number of reasons - participation levels, diverse goals and direct vs. indirect type of impacts (Larson et al., 2015; 2014; Poortinga et al., 2004). Likewise, it refers to purchase and use products that have environment impact (Stern, 2000). It is often said that environmental attitudes and environmental behavior are related to people's values (Poortinga et al., 2004). Values are typically conceptualized as important life goals or standards that serve as guiding principles in life (Rokeach, 1973). Many studies have shown that the values contribute to explain various environmental behaviors and attitudes. Hence, changes in attitudes would influence behavior (Aizen and Fishbein, 2005). On one hand, values were significantly correlated to various self-reported behaviors such as recycling behavior and consumer behavior to protect the environment (Karp, 1996). On the other hand, the studies of other researchers 


\section{$\begin{array}{lll}\text { Pretest } \mathrm{T}_{0} & \text { Intervention } \mathrm{X}_{\mathrm{E}} & \text { Posttest } \mathrm{T}_{\mathbf{1}}\end{array}$}

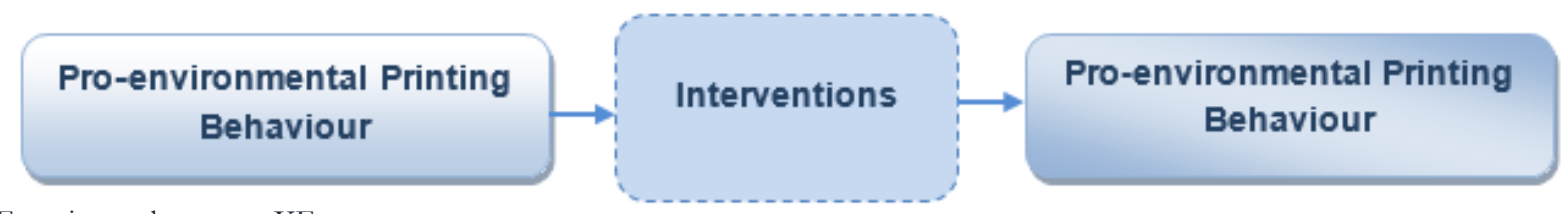

Experimental group $=\mathrm{XE}$

Figure 1. The experiment group and control group's pretest-posttest design

showed that values are related to recycling behavior and it is people's willingness to take action to protect the environment (Dunlap et al., 1983; Stern and Dietz, 1994). Therefore, planned behavior is the individuals' intention to perform a given behavior - the stronger the intention to engage in a behavior, the more likely should be its performance (Aizen, 1991).

Thus, it can be said - less use of paper means less cutting of trees which will leads to a sustainable approach of life. The whole concept of the earth is like a big balloon where economy and ecology are the small balloons. If economic balloon will grow more in proportion, it will smother the others; i.e. lives on the earth (Cavagnaro, 2012). Therefore at work printing should not be seen as comfort and economical but as a sustainable aspect as well. Enhancing pro environmental printing behaviour at work would reduce costs both financially and environmentally. Printing is a key area of unnecessary environmental and financial waste (McCool, 2008).

The purpose of this study is to find out teachers' pro-environmental printing behaviour at the schools. Considering the aforementioned literature review, this study observes the following: does pro-environmental printing behavior save financial and economic cost?

\section{RESEARCH METHOD}

This research is based on observation and the collection of print-data are the instruments to gather data. Observation was carried out during the pretest and posttest phase for the experiment group as well as for the control group. This study is recapitulated into three phases: Phase one represents zero measurement and in this phase, printing data is gathered. Phase two represents the execution of interventions, the role of the intervention is to provide support to phase one to accomplish phase three's objectives. During this phase, intervention is designed and implemented on the experimental group only; whereas phase three measures the reduction of printing paper. After collecting the pre-test and posttest, print-data is analyzed to form the conclusion. Seven different elementary schools have taken part in this study. The schools are divided in two groups; experimental 57 participants and control 51 participants. The experimental group has received the following treatment: green printing posters were placed on the computer halls and by the printers during the intervention week one and week two to promote pro environmental printing behavior.

The following conceptual map design is set for the pretest-posttest for collecting print-data. Two symmetrical groups are formed, namely, the experimental group and control group. An initial measurement observation (pretest) is received by both groups. Subsequently, the experimental group receives the intervention which is also referred to as intervention group, whereas, the control group receives no treatment at all.

The amount of the paper consumption in the school is logged and observed $\left(\mathrm{T}_{0}\right)$. Furthermore, data from each printer is gathered digitally. The intervention $\left(\mathrm{X}_{\mathrm{E}}\right)$ is implemented on the experimental group. A posttest is measured to record performance after the intervention which is named $\left(T_{1}\right)$. The experiment group and control group's pretest-posttest design is represented by the following formula shown in Figure 1: $\mathrm{T}_{0}-\mathrm{X}_{\mathrm{E}}-\mathrm{T}_{1}$.

The intervention is executed for two weeks and printing data is collected two times for five days from the experimental and control group but the intervention is carried out only on the experimental group. Proenvironmental printing posters are placed on the computer halls and by the printers. It is noticed that the experimental group printed $45 \%$ to $51 \%$ less during intervention.

\section{FINDING AND ANALYSIS}

Out of 108 participants, a total of $18 \%$ of them were male and $82 \%$ female which indicates a real picture of elementary schools under consideration and in general all over The Netherlands (CBS report, 2012).

Moreover, 69\% teachers were above 40 and only 11\% were younger than 30 years indicating that there are more elderly staff in the elementary schools which is also in line with the population of the schools (CBS report, 2012). 


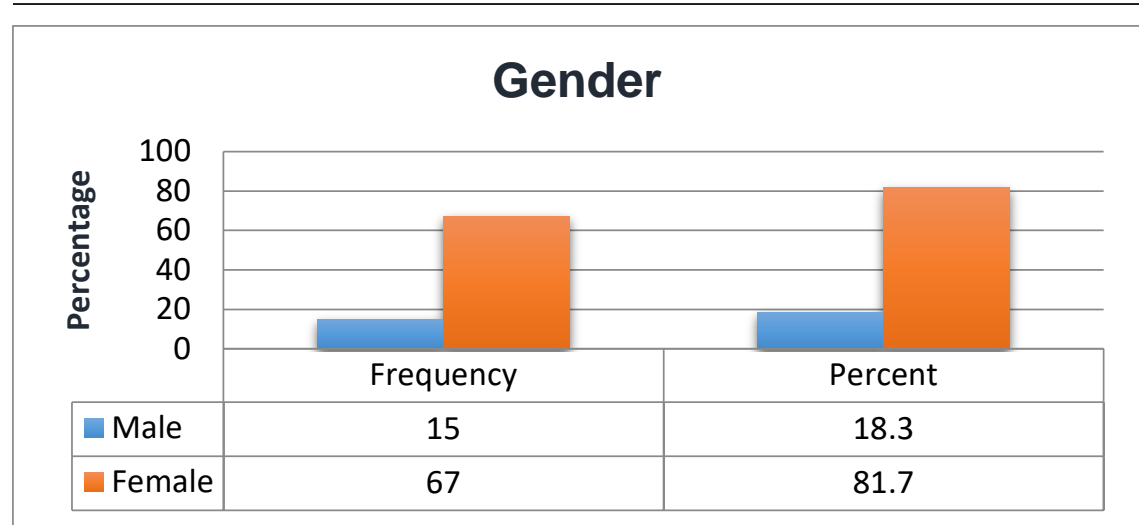

Figure 2. Gender of the participants

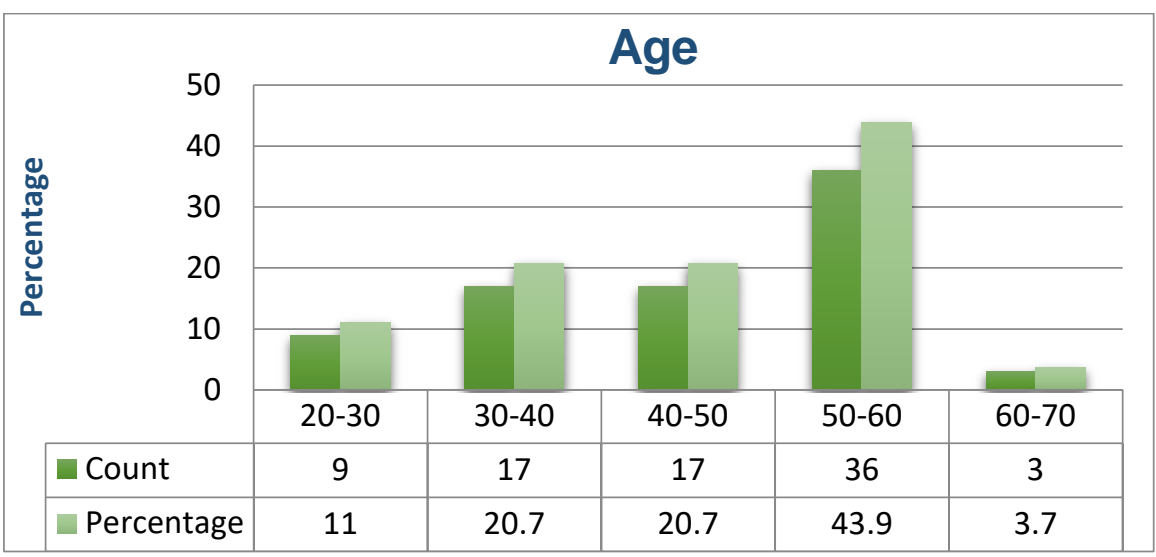

Figure 3. Age of the participants

Table 1. Experimental and Control group summary of paper consumption per user per day

\begin{tabular}{lcccc}
\hline Name school \& Group & Pretest 30 days & Intervention W1 & Intervention W2 & Posttest 20 days \\
\hline Sch1 (exp.) & 0,76 & 0,82 & 0,85 & 1,21 \\
\hline Sch2 (exp.) & 0,47 & 0,55 & 0,33 & 0,74 \\
\hline Sch3 (exp.) & 0,63 & 0,35 & 0,45 & 0,57 \\
\hline Sch4 (Cont.) & 0,69 & $0,34^{* *}$ & $0,31^{* *}$ & 0,70 \\
\hline Sch5 (Cont.) & 0,72 & 0,81 & 0,49 & 0,71 \\
\hline Sch6 (Cont.) & 0,99 & 1,91 & 1,41 & 0,93 \\
\hline Sch7 (Cont.) & 1,10 & 0,83 & 0,67 & 1,74 \\
\hline
\end{tabular}

**Sch.4 director put quota on printing

\section{Printing Data Observation}

The objective of printing data observation is to find out teachers' pro environmental printing behavior at schools. Furthermore, the role of the intervention is a mediator and provides support to phase one to accomplish phase three's objectives. More details can be found in the intervention and the pretest - posttest of this study.

Table 1 indicates printing data of experimental and control group. It is observed in three phases, namely, pretest, intervention and posttest for all the seven schools. However, sch.1, 2 and 3 belong to the experimental group (exp.) and sch.4, 5, 6 and 7 belongs to the control group (cont.). Underneath, further details of the tests are presented.

\section{Pretest Outcomes}

During the pretest, data was collected for thirty days from experimental and control group as shown in the Figure 4. X-axis represents school names where green color is designated to experimental group and blue color epitomizes control group whilst y-axis signifies consumption of paper per user per day. During this period, printers of the schools were observed and exceptionalities were noted. It has been observed that sch. $2($ Mean $=0,47)$ has an extra stencil machine and it has been used if the school has extra assistance available from parents or volunteers. Furthermore, sch. 6 (Mean =0,72) has two buildings and they have one central printer only in the main building, therefore, many students and teachers of the other building print the same document many times causing a lot of wastage of paper. 


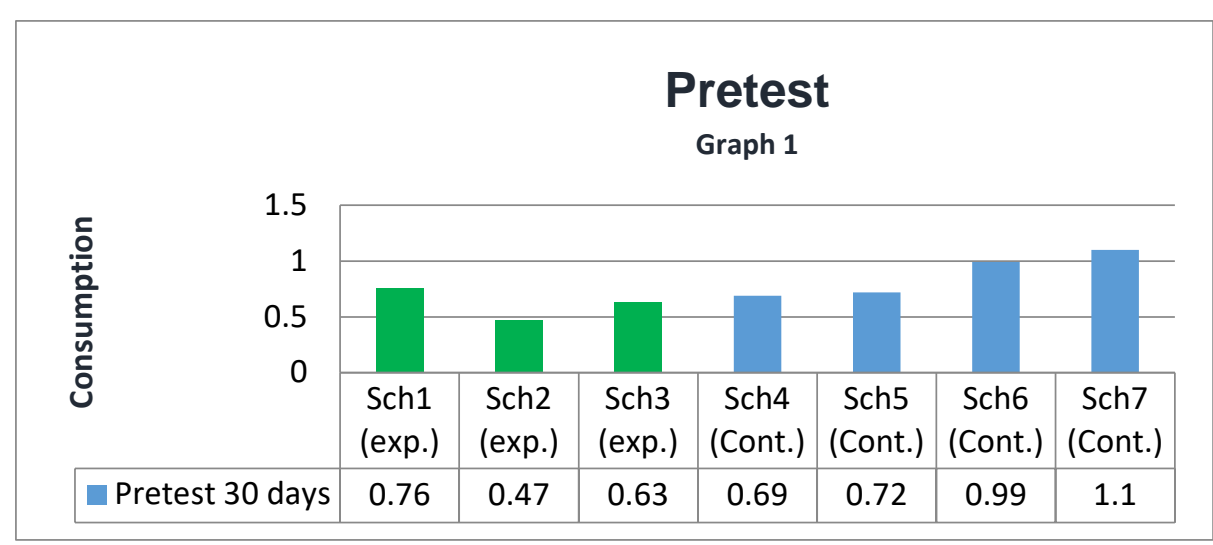

Figure 4. Data collected for thirty days from experimental and control group in Pretest phase

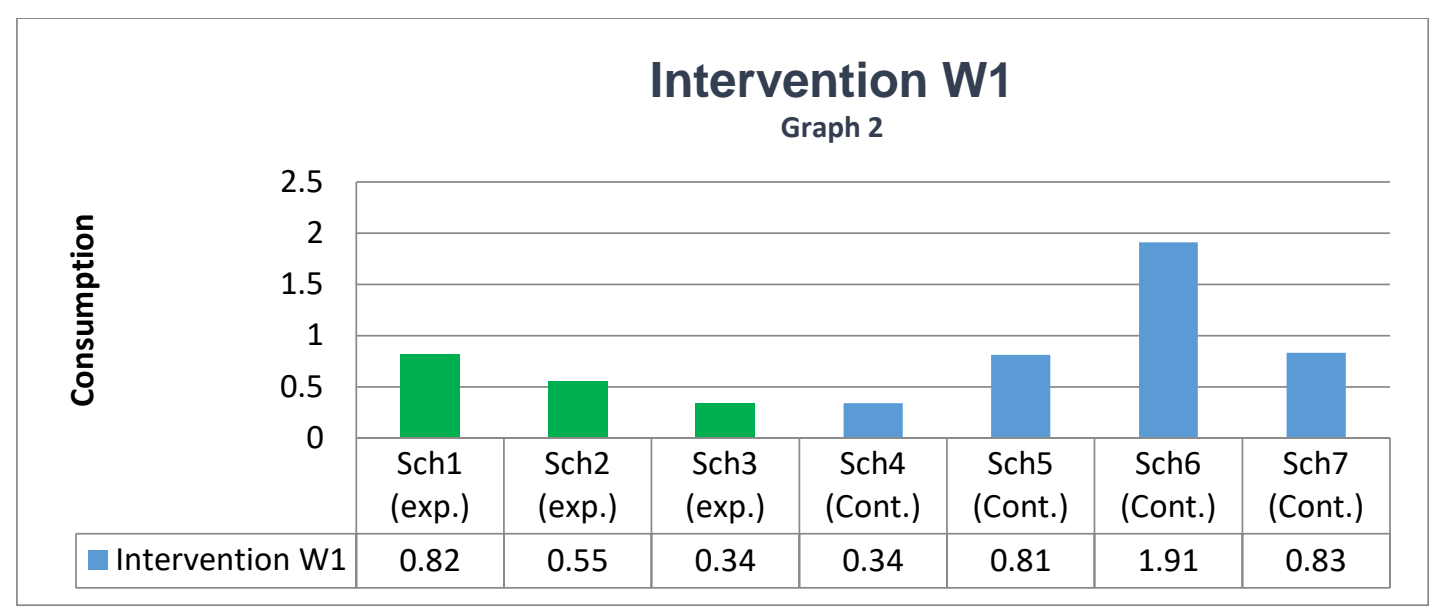

Figure 5. Data collected for five days from experimental and control group in Intervention phase

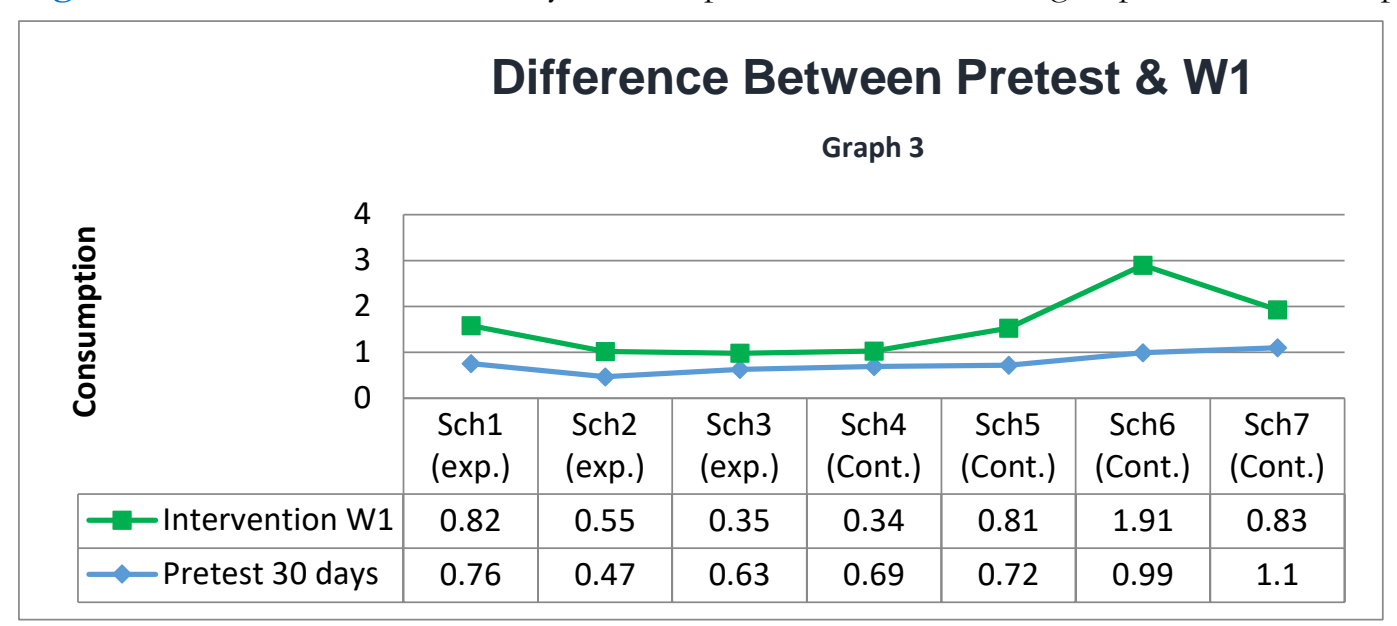

Figure 6. Difference between Pretest \& W1

\section{Intervention W1}

As shown in Figure 5 during this phase, printing data was collected for five days from experimental and control group but the intervention took place only on the experimental group by promoting pro environmental printing behavior. X-axis represents school names where green color is designated to experimental group and blue color exemplify control group whilst y-axis indicates consumption of paper per user per day. Green printing posters were placed on the computer halls and by the printers.

Figure 6 reveals the results of the first week intervention, where $\mathrm{x}$-axis represents school names where green color is designated to intervention week one and blue color epitomize pretest whilst y-axis signifies consumption difference between them. Furthermore, the figure indicates that there is an obvious difference in consumption by sch.3 namely ( $M=0,63$ to $M=0,35)$ per day which is $45 \%$ lesser than the pretest. However, there was another unplanned intervention which took place during this week. The director of sch.4 introduced quota system for teachers to print $(M=0,69$ to $M=0,34)$ and this indicates that $51 \%$ lesser printing occurred during that week. It 


\section{Intervention W2}

Graph 4

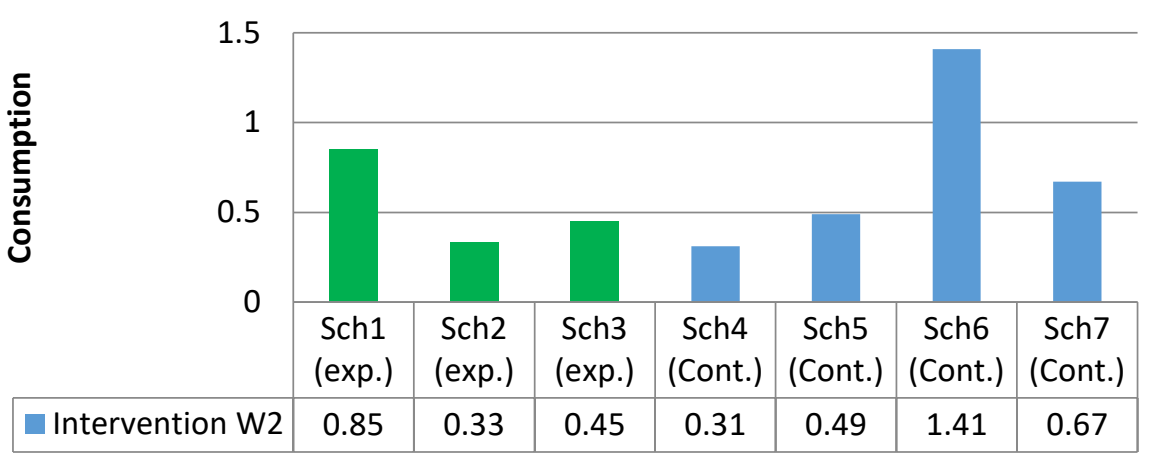

Figure 7. During this phase, printing data was again collected for five days from both the experimental and control group

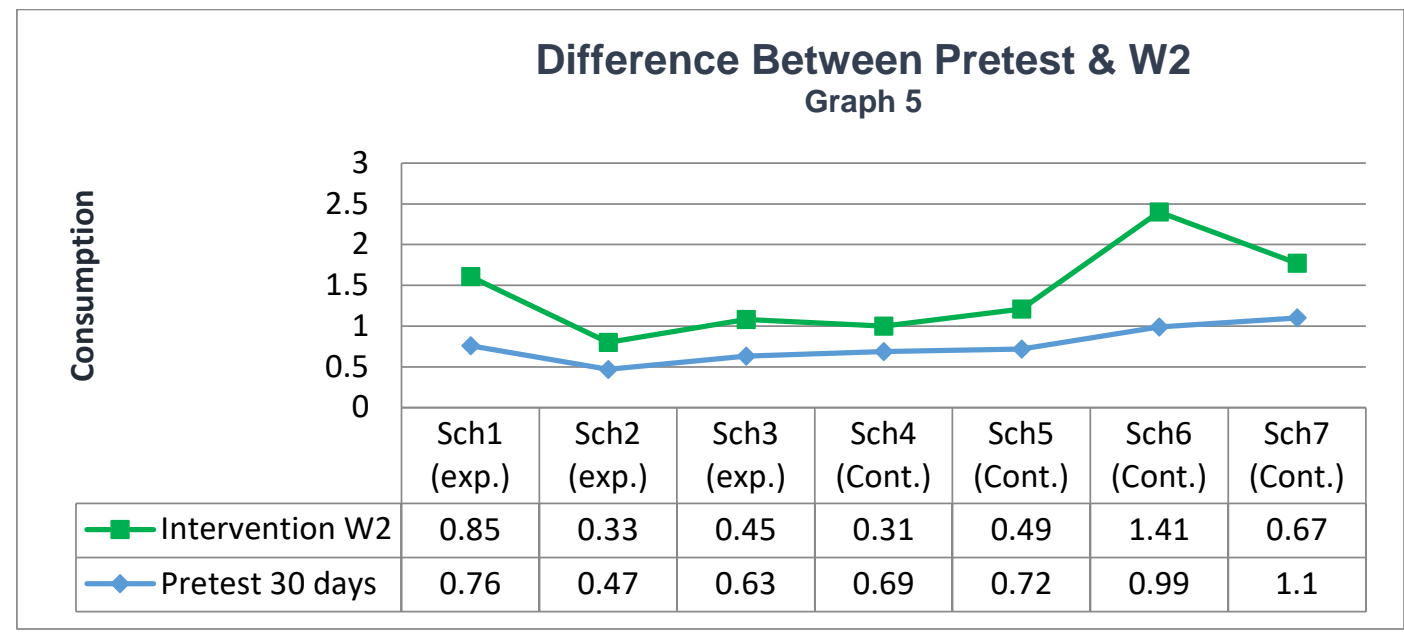

Figure 8. The results of the second week intervention

shows that teachers' pro environmental printing behavior has positive influence on the printing; hence, saving paper and pro environmental costs for elementary schools.

\section{Intervention W2}

As shown in Figure 7, during this phase printing data was again collected for five days from both the experimental and control group. X-axis represents school names where green color is nominated to experimental group and blue color symbolize control group whilst y-axis indicates consumption of paper per user per day. Intervention took place only on the experimental group by placing another set of green printing posters on the computer halls and by the printers.

Figure 8 reveals the results of the second week intervention, where x-axis represents school names where green color is designated to intervention week two and blue color represent pretest whilst y-axis indicates the consumption difference between them. Furthermore, the figure indicates that there is a difference in consumption by the sch. 2 and sch.3, namely, $(M=0,47$ to $M=0,33)$ and $(M=0,63$ to $M=0,45)$ per day which is $30 \%$ and $29 \%$ lesser than the pretest. However, there was another unplanned event during this period as mentioned in the intervention W1. In W2 sch.4 printed 55\% lesser than the pretest ( $\mathrm{M}=0,69$ to $\mathrm{M}=0,31)$. It shows teachers' pro environmental printing behavior has a positive influence on the printing indicating less printing at school and hence, saving paper and environmental cost.

\section{Posttest}

Figure 9 represents that during posttest, data is collected for twenty days from both the experimental and control group. X-axis signifies school names where green color is designated to experimental group and blue color represent control group whilst y-axis shows consumption of paper per user per day. After comparing these results with the pretest outcomes, it is observed that there is a substantial printing growth by sch.1 ( $\mathrm{M}=0,76$ to $\mathrm{M}=$ 1,21) and sch.7 (M=1,10 to $M=1,74)$. In contrast, other school results are more or less the same for the pretest and the posttest. Though the noticeable feature is after the second intervention, each school's pro- environmental 


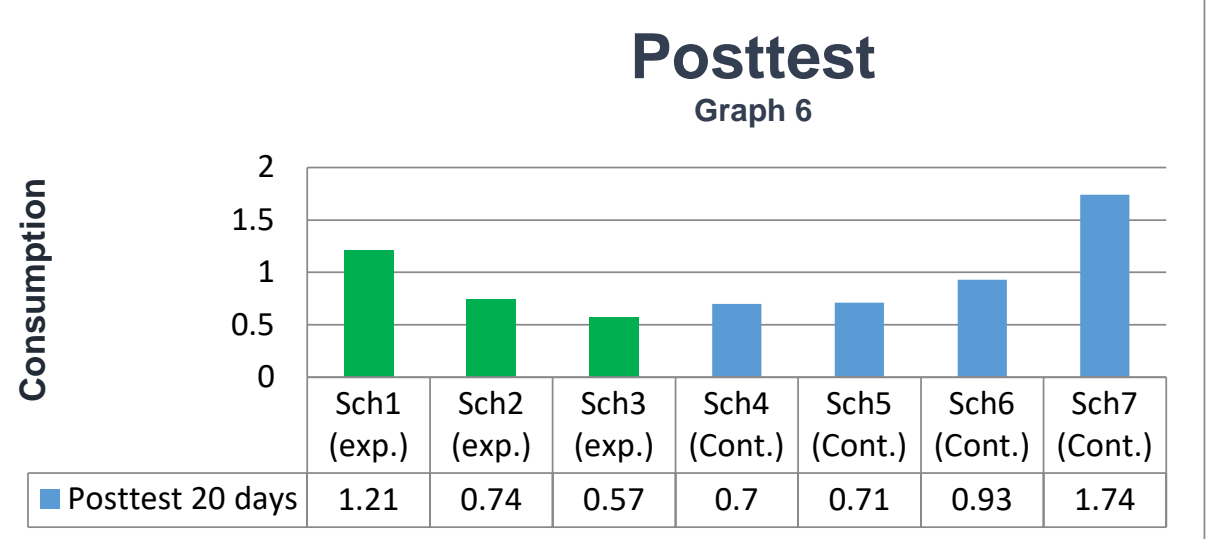

Figure 9. During posttest, data is collected for twenty days from both the experimental and control group

printing behavior is altered and there is an increase in printing. That indicates that if teachers are conscious about their pro environmental printing behavior, results are improved and there is less printing.

Considering the outcomes of the printing data, an observation following the hypotheses is formed.

\section{Intervention has a Positive Effect on Pro-environmental Printing Behavior}

During intervention week one and two sch.3's ( $\mathrm{M}=0,63$ to $\mathrm{M}=0,35, \mathrm{M}=0,45)$ results indicate that there is a significant positive influence on teachers' pro environmental printing behavior. Furthermore, sch. 2 has a significant difference in the second week ( $\mathrm{M}=0,47$ to $\mathrm{M}=0,33$ ) which also indicates intervention has positive influence on teachers' pro environmental printing behavior. Besides, the initiation of the director of sch. 4 to introduce quota system for printing has produced positive results as well $(M=0,69$ to $M=0,34 \& M=0,31)$ that also specifies that if teachers are on the alert then printing decreases. Hence, it indicates that the intervention was successful and has a positive effect on pro environmental printing behavior leading to less printing and less paper cost in the end at elementary schools; whilst, sch.1 has no reduction in the printing as the school has its annual school auditing during this time.

Considering the presented results and analysis of this study, a conclusion is drawn. Teachers' awareness about pro environmental behavior has a positive influence on pro environmental printing behavior. This is in line with the previous study, less use of paper can decrease both financial and environmental costs (McCool, 2008).

\section{DISCUSSION}

\section{What is the Economic and Environmental Impact of Reduction in Printing at Elementary Schools?}

The results of this study reveal that during intervention $45 \%$ to $51 \%$ use of printing paper is reduced - hence, less use of paper at elementary schools means less environmental and financial costs. For instance, thinking before printing can save $28 \%$ paper, therefore, schools can protect one tree within 2 months. 1 tree $=16.67$ reams $=8333$ sheets. The previous research has shown that 1410 pages per year can be saved, if the wastage is less than 6 pages per day. In case of schools having 18 teachers $(18 \times 1410 / 8333=3)$ schools can then protect 3 trees per year (Green Facts, 2004). The results of previous study indicate that less use of paper can reduce both financial and environmental costs (McCool, 2008). Moreover, paperless workflow in offices has reduced the environmental and economic costs (Kutami, 2009).

\section{What is the Effect of Pro-environmental Behaviour in Reducing Printing?}

The findings of this study show that teachers' pro-environmental behaviour have a positive influence on printing. The previous study reveals that biospheric values provide a distinct basis for pro-environmental intentions (De Groot and Steg, 2008). This is also in line with Cavagnaro and Curial's (2012) TLS framework stating that sustainability is "an inside out process, as it starts and ends with people" (p. 272). Thus, teachers' pro environmental behaviour reduce printing at elementary schools; therefore less economic and environmental costs.

\section{Teachers' Pro-environmental Printing Behaviour Can Reduce Environmental and Financial Costs at Elementary Schools Measured as Use of Paper.}

The results of this study confirm that pro-environmental behaviour is the significant element to influence printing behavior. The results of printing data during the intervention also confirm the substantially less amount of paper used, which is in line with previous literature review (Kutami, 2009; McCool, 2008; Dee, 2010; Thompson, 
2009). Paper reduction is often a fairly simple way to reduce costs and increase company value (Citigroup, 2004). According to previous research, individuals with a pro-environmental value approach will primarily form their choice to act pro environmentally or not, on the apparent costs and benefits for the environment and planet all together (De Groot and Steg, 2008). Therefore, high pro environmental printing behavior means less printing at school which leads to less use of paper at elementary school; thus, saving financial and environmental costs. Hence, the hypothesis is supported.

\section{LIMITATIONS}

There were few limitations found during data analysis such as:

First of all, during the pretest printing data gathering - as the scanner of sch.7 was out of order for two weeksthe users were not able to scan their documents and had to print. Although the scanner was suspected to be the reason for extra printing at school, the results of the posttest reveal that the scanner was not the significant reason as the school has more printing ratio than other schools.

Secondly, during intervention one and two, sch.1 (experimental group) had to undergo an annual audit; therefore, extra documentation took place and hence more printing during those weeks meaning the accurate pro environmental printing influence could not be measured.

\section{CONCLUSION AND RECOMENDATION}

The outcomes of this study confirm that teachers' biospheric values have a positive impact on the pro environmental printing behavior at the schools. This means if schools are able to promote biospheric values orientations among teachers, the schools can minimize their financial and environmental costs.

Keeping the conclusion in view, the following recommendations are offered as guidelines for consideration and possible application by the school management in dealing effectively with the pro-environmental printing behavior.

$>$ To promote pro-environmental printing behavior at schools, the directors of the schools should promote digitalization in their schools such as digital documentation and digital communication at schools.

This study is carried out within seven elementary schools and is exclusively allocated for teachers' pro environmental printing behaviour; however, students did not take part in this research. To find out the influence of teachers' pro-environmental printing behaviour on students, further information could be obtained from the students as well. Additionally, a similar study could be carried out in colleges and universities.

\section{REFERENCES}

Aizen, I. (1991). The Theory of Planned Behavior. Organizational behavior and buman decision processes, 50, 179-211. https://doi.org/10.1016/0749-5978(91)90020-T

Aizen, I. (1991). The Theory of Planned Behavior. Organizational behavior and human decision processes, 50, 179-211.

Aizen, I. and Fishbein, M. (2005). The influence of attitudes on behavior. The handbook of attitudes, 173, 221.

Brundtland, G. H. (1987). Sustainable development. Available at: http:// en.wikipedia.org/wiki/Sustainable_development\#Definition

Cavagnaro, E. and Curiel, G. H. (2012). The Three Levels of Sustainability, Sheffield: Greenleaf Publishing Ltd.

Centraal Bureau voor de Statistiek. (2012). Jaarboek onderwijs in Cijfers. Available at: http:/ / www.cbs.nl/NR/rdonlyres/3036B4E1-A671-4C9E-95BF-90C0493B4CD9/0/2012f162pub.pdf.

Citigroup. (2004). Environmental defense partnership to improve office paper management. (pp. 1-44) Available at: http://apps.edf.org/documents/4138_Final\%20Citigroup\%20report_11-1-04.pdf

De Groot, J. and Steg, L. (2008). Biospheric Value Orientations Significant Behavior: How to Measure Egoistic, Altruistic, and Value Orientations to Explain Beliefs Related to Environmental, Environment and Bebavior, 40, 330. https://doi.org/10.1177/0013916506297831

Dee, J. (2010). Sustainable growth, Melbourne, Australia: Sensis.

Dunlap, R. E., Grieneeks, J. K. and Rokeach, M. (1983). Human values and pro-environmental behavior. Energy and material resources: Attitudes, values, and public policy. Boulder, CO: Westview.

Gifford, R. (2011). The Dragons of Inaction: Psychological Barriers that Limit Climate Change Mitigation and Adaptation. American Psychologist, 66(4), 290-302. Available at: http://www.scpknowledge.eu/sites/default/files/knowledge/attachments/The\%20Dragons\%20of\%20Inact ion.pdf. https://doi.org/10.1037/a0023566 
Green Facts. (2004). Environment, Canada, iD2 communication. Available at: http:/ / www.id2.ca/downloads/eco-design-paper-facts.pdf

Gregory, R. (1971). Biochemistry of Photosynthesis University Press, Belfast.

Karp, D. G. (1996). Values and their effect on pro-environmental behavior. Environment and Behavior, 28(1), 111133. https://doi.org/10.1177/0013916596281006

Kutami, M. (2009). Using ICT to reduce burden on the environment. "New Breeze" the journal of the ITU Association of Japan, 2(4). Available at: http://www.itu.int/net/itunews/issues/2009/10/14.aspx

Larson, L., Stedman, R., Cooper, C. and Decker, D. (2015). Understanding the multidimensional structure of proenvironmental behavior. Journal of Environmental Psychology, 43, $112-124$. https://doi.org/10.1016/j.jenvp.2015.06.004

McCool, C. (2008). How to Reduce Printing Costs by 17\%. Green Print Technologies, (p. 2), Version 1.1, Available at: www.printgreener.com

Poortinga, W., Steg, L. and Vlek, C. (2004). Values, environmental concern, and environmental behavior a study into household energy use. Environment and behavior, 36(1), 70-93. https://doi.org/10.1177/0013916503251466

Rokeach, M. (1973). The nature of human values. New York: Free Press.

Steg, L. and Vlek, C. (2008). Encouraging pro-environmental behavior: An integrative review and research. Journal of Environmental Psychology, 29(1), 309-317.

Steg, L. and Vlek, C. (2009), Encouraging Proenvironmental Behavior: An Integrative Review and Research Agenda. Journal of Environmental Psychology, 29, 309-317. Available at: http:/ / www.rug.nl/staff/e.m.steg/stegvlekencoura ging.pdf. https://doi.org/10.1016/j.jenvp.2008.10.004

Stern, P. C. (2000). Towards a coherent theory of environmentally significant behavior. Journal of Social Issues, 56(3), 407-424. https://doi.org/10.1111/0022-4537.00175

Stern, P. C. and Dietz, T. (1994). The value basis of environmental concern. Journal of Social Issues, 50(3), 65-84. https://doi.org/10.1111/j.1540-4560.1994.tb02420.x

Suleri, J. (2013). Journal One PVC, Leeuwarden: Stenden University, 1-7.

Tan, M. P. (2016). GO GREEN! Available at: http://pmas.sg/wpcontent/uploads/2016/07/PrintSingapore_2016_02_EB.pdf

Thompson, J. (2009). Three approaches to green computing on campus. Educause Quarterly, 32(3).

Veen, W. (1993a). The role of beliefs in the use of information technology: implications for teacher education, or teaching the right thing at the right time. Journal of Information Technology for Teacher Education, 2(2), $139-153$. https://doi.org/10.1080/0962029930020203

Veen, W. (1993b). How Teachers Use Computers in Instructional Practice: four case studies in a Dutch secondary school. Computers and Education, 21(1/2), 1-8. https://doi.org/10.1016/0360-1315(93)90041-G 